\title{
High-value organic acid recovery from first-generation bioethanol dunder using nanofiltration
}

\author{
Jeraz Coopera, Yun Ye ${ }^{a}$, Amir Razmjou ${ }^{a,{ }^{*}}$ and Vicki Chen ${ }^{a, b, *}$ \\ aUNESCO Centre for Membrane Science and Technology, School of Chemical Engineering, The University of New \\ South Wales, Sydney 2052, Australia \\ ${ }^{b}$ School of Chemical Engineering, University of Queensland, Queensland 4072 Australia \\ *Corresponding authors: E-mail address: amirr@unsw.edu.au and v.chen@uq.edu.au
}

\section{Supporting Information}

\section{Membrane characterisation}

Membrane permeability, calculated from the slope of Flux vs TMP profiles for each of the three membranes is presented in Figure SI. All trendlines exhibit a correlation/regression coefficient greater than 0.995 indicating sound linearity with successive increments in TMP. Despite the absence of a distinct molecular weight cut-off (MWCO), NF membranes are instead classified based on the rejection of species across a range of MWCO values. Therefore, application of a relatively tight membrane such as NF90 entails a lower permeability $\left(5.63 \mathrm{~L} / \mathrm{m}^{2} \mathrm{~h} \cdot \mathrm{bar}\right)$ than NF270 (15.2 L/m²h-bar). Contrary to expectations, the permeability of NTR-7450 was found to be only slightly higher than that of NF90 despite having the largest MWCO of all membranes examined in the present study. This is most likely attributed to a strongly hydrophobic active layer, a notion corroborated through measurements of the contact angle in the literature ${ }^{1,2}$. 


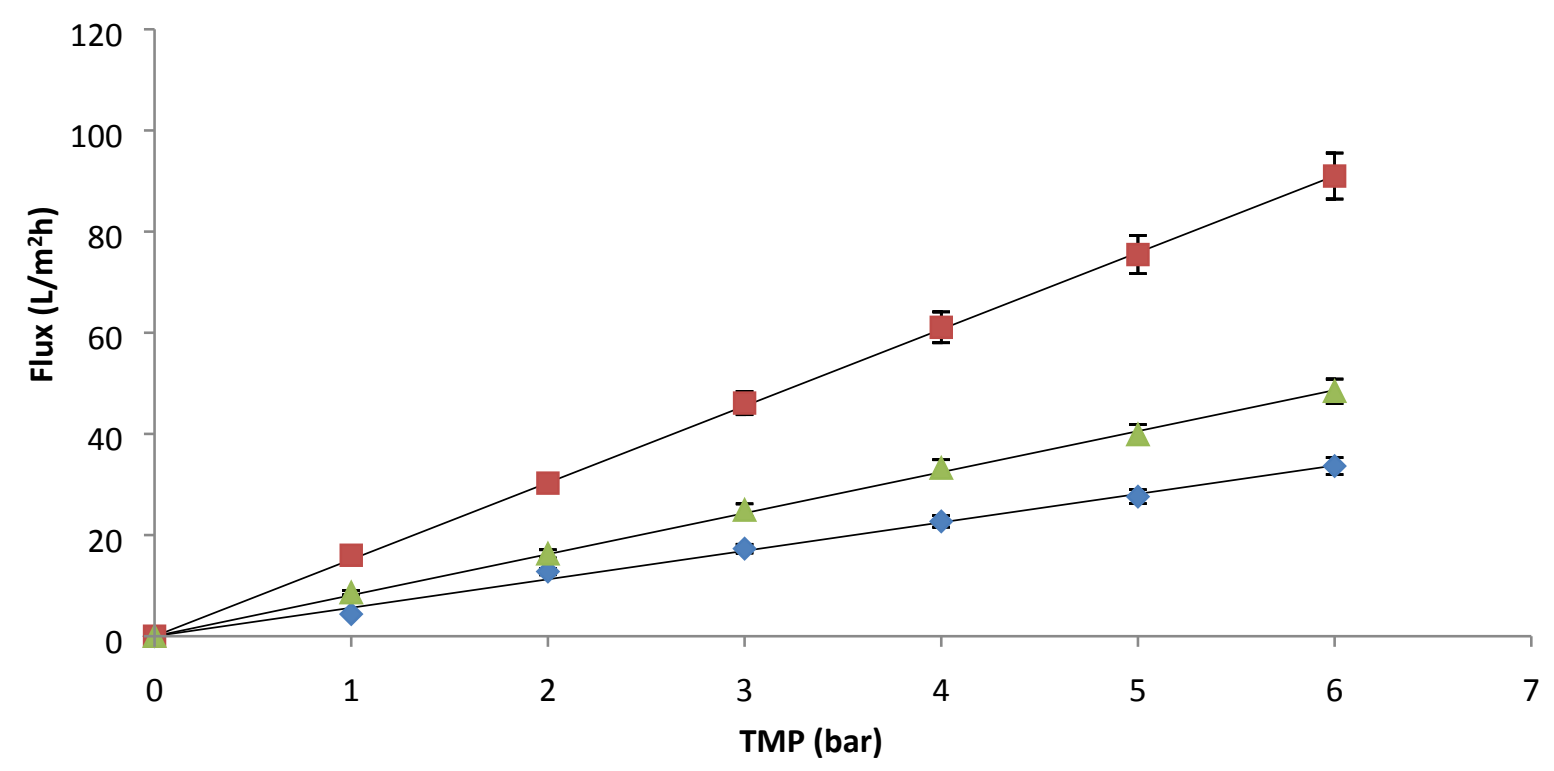

Figure S1: Successive measurements of deionised water flux with varying TMP for determination of membrane permeability

\section{Foulant layer analysis - SEM imaging}

Surface analysis via SEM imaging and EDX spectroscopy were used to provide insight into the nature of foulants adsorbed on the surface or within pores of the NF270 membrane, see Figure S2 and Figure S3.

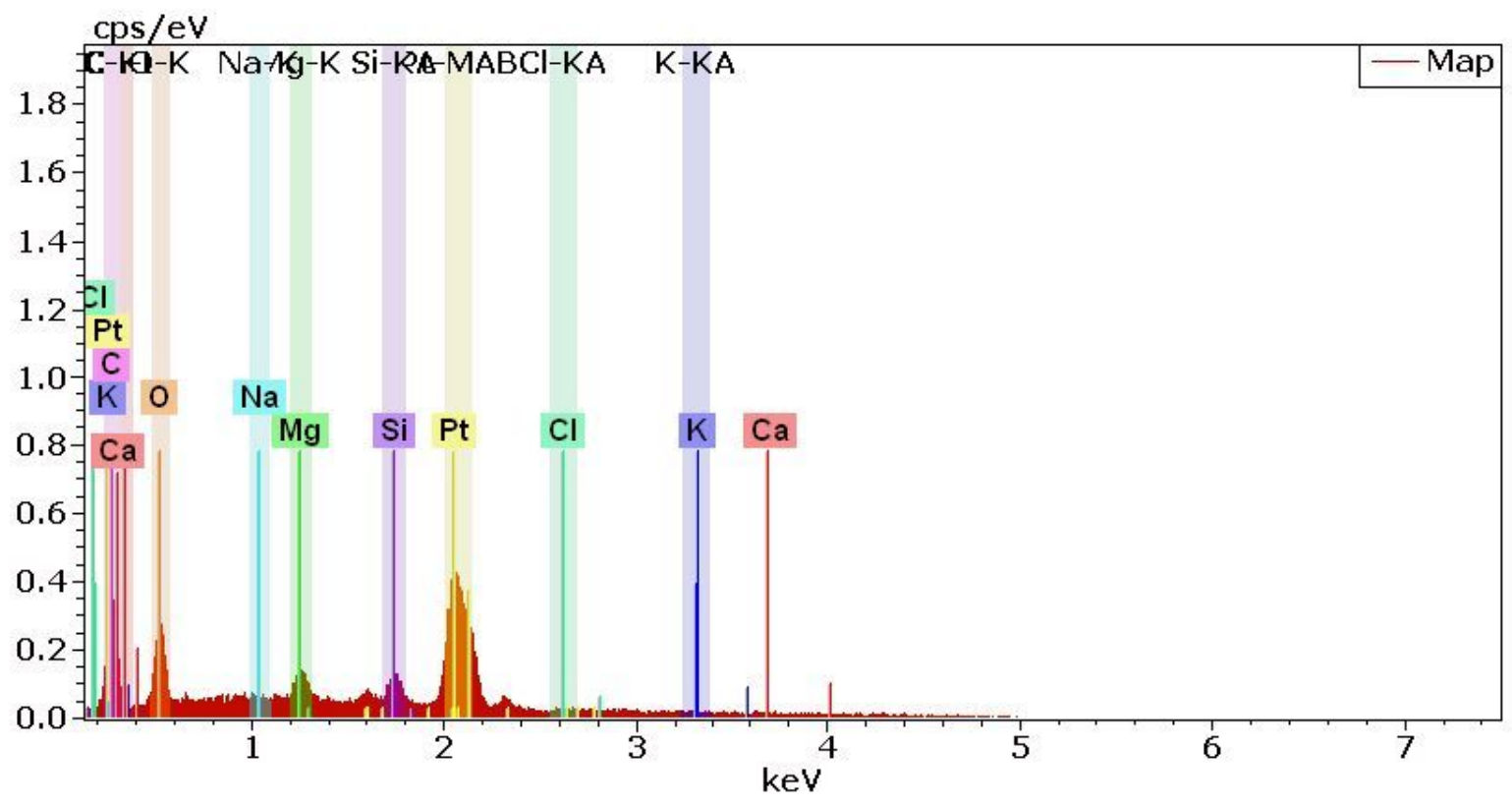

Figure S2: EDX spectra for fouled NF270 membranes 

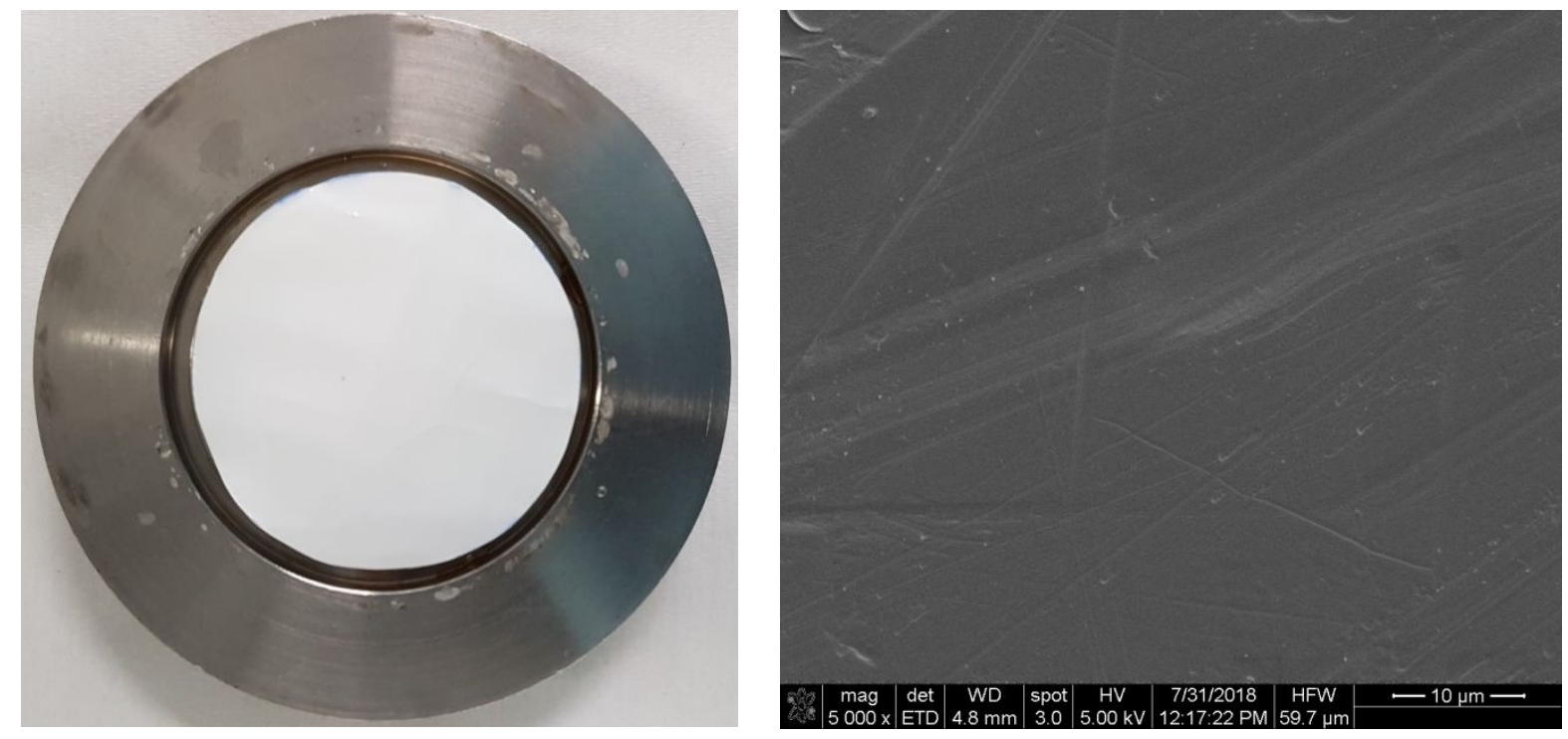

(a)
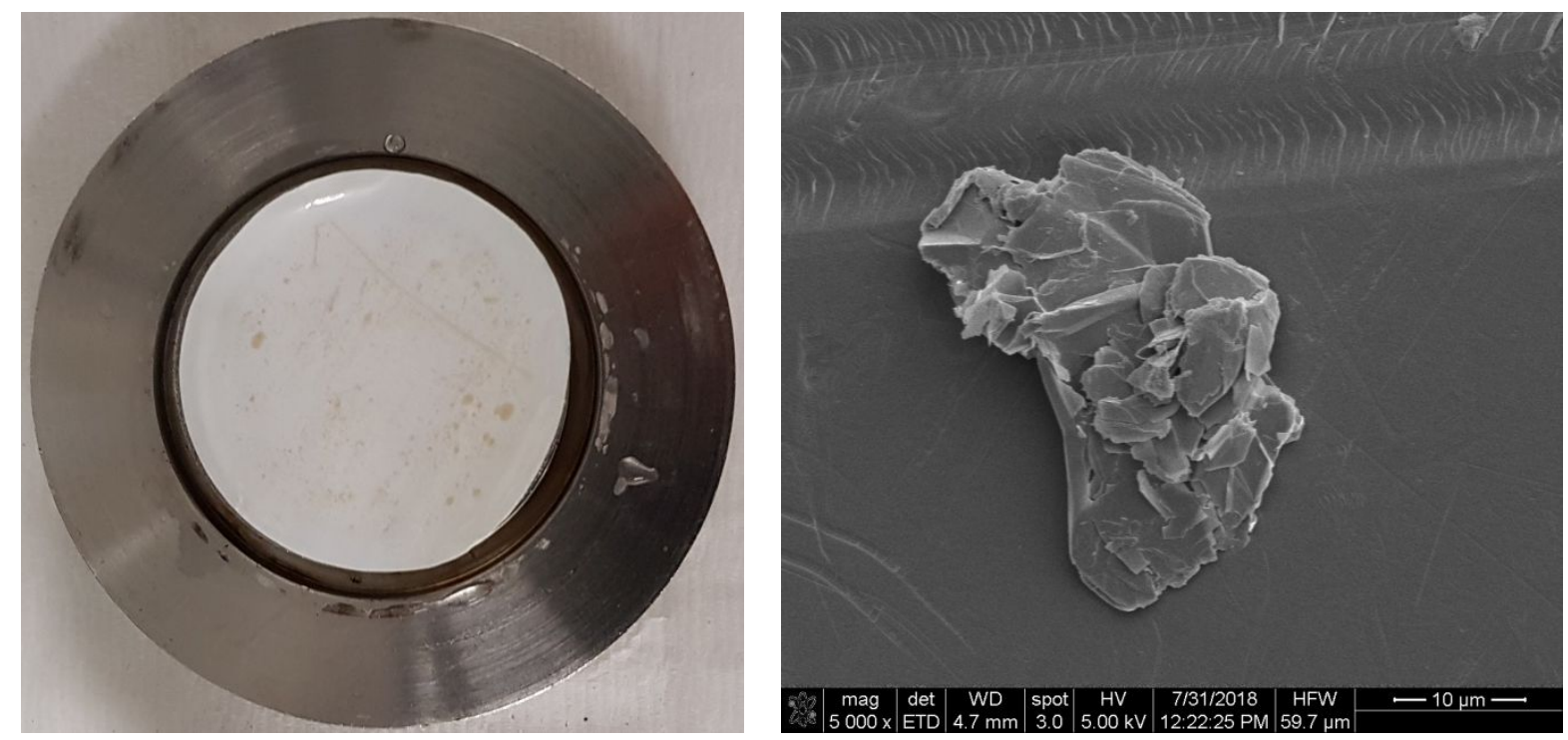

(b)

Figure S3: Visual examination followed by SEM analysis of (a) virgin and (b) fouled NF270 membranes $(5000 \mathrm{X})$

EDX spectra shows a high signal intensity for $\mathrm{Pt}, \mathrm{C}$, and $\mathrm{Ca}$ of around $0.4 \mathrm{keV}$ together with smaller quantities of $\mathrm{O}$ (around $0.27 \mathrm{keV}), \mathrm{Mg}(0.1 \mathrm{keV})$ and $\mathrm{Si}(0.1 \mathrm{keV})$. Of course a high signal intensity is expected for Pt due to coating of the membrane for surface analysis, however the presence of other species in particular $\mathrm{C}$ and inorganic ions of $\mathrm{Ca}$ and $\mathrm{Mg}$ corroborates the notion of humic acid macromolecular bonding onto the surface as is noted in Figure $\mathbf{S 3} \mathbf{~ b}$. Although it is difficult to state explicitly or definitively whether this is the case, however bridging of free humic acid functional 
groups by divalent inorganics is a possible outcome for increasing the deposition of foulants onto the membrane surface ${ }^{3-5}$. Direct visual examination of virgin and fouled membranes (left-hand pane of Figure S3) indicates the distribution of dark-brown colour is not uniform throughout the membrane, and instead occurs in agglomerates or patches on the surface. Consequently, this further reinforces the presumption of humic acid macromolecular bonding onto the membrane.

\section{References}

1. Boussu, K.; Van der Bruggen, B.; Volodin, A.; Van Haesendonck, C.; Delcour, J. A.; Van der Meeren, P.; Vandecasteele, C., Characterization of commercial nanofiltration membranes and comparison with self-made polyethersulfone membranes. Desalination 2006, 191 (1), 245-253.

2. Tang, C. Y.; Kwon, Y.-N.; Leckie, J. O., Effect of membrane chemistry and coating layer on physiochemical properties of thin film composite polyamide RO and NF membranes: II. Membrane physiochemical properties and their dependence on polyamide and coating layers. Desalination 2009, 242 (1), 168-182.

3. Al-Amoudi, A. S., Factors affecting natural organic matter (NOM) and scaling fouling in NF membranes: A review. Desalination 2010, 259 (1), 1-10.

4. Mänttäri, M.; Puro, L.; Nuortila-Jokinen, J.; Nyström, M., Fouling effects of polysaccharides and humic acid in nanofiltration. Journal of Membrane Science 2000, 165 (1), 1-17.

5. Wang, Z.; Zhao, Y.; Wang, J.; Wang, S., Studies on nanofiltration membrane fouling in the treatment of water solutions containing humic acids. Desalination 2005, 178 (1), 171-178. 